\title{
The second pregnancy has no effect in the incidence of macrosomia: a cross-sectional survey in two western Chinese regions
}

Li Luo ${ }^{1,2,3,4}$, Huan Zeng ${ }^{1,2,3}$, Mao Zeng ${ }^{1,2,3}$, Xueqing Liu' ${ }^{1}$, Xianglong $X u^{1,2,3,4,5}$, Lianlian Wang ${ }^{5,6,7,8^{*}}$ and Yong Zhao ${ }^{1,2,3^{*}}$

\begin{abstract}
Background: After the implementation of the universal two-child policy in China, the increase in parity has led to an increase in adverse pregnancy outcomes. The impact of one and two fetuses on the incidence of fetal macrosomia has not been fully confirmed in China. This study aimed to explore the differences in the incidence of fetal macrosomia in first and second pregnancies in Western China after the implementation of the universal two-child policy.

Methods: A total of 1598 pregnant women from three hospitals were investigated by means of a cross-sectional study from August 2017 to January 2018. Participants were recruited by convenience and divided into first and second pregnancy groups. These groups included 1094 primiparas and 504 women giving birth to their second child. Univariate and multivariate logistic regression analyses were performed to discuss the differences in the incidence of fetal macrosomia in first and second pregnancies.

Results: No significant difference was found in the incidence of macrosomia in the first pregnancy group (7.2\%) and the second pregnancy group (7.1\%). In the second-time pregnant mothers, no significant association was found between the macrosomia of the second child (5.5\%) and that of the first child (4.7\%). The multivariate logistic regression model showed that mothers older than 30 years are not likely to give birth to children with macrosomia (odds ratio (OR) 0.6, 95\% confidence interval (Cl) 0.4,0.9).
\end{abstract}

Conclusions: The incidence of macrosomia in Western China is might not be affected by the birth of the second child and is not increased by low parity.

Keywords: Fetal macrosomia, China, Parity, Cross-sectional study, Incidence

\section{Background}

Fetal macrosomia is a term used to define a newborn that is significantly larger than average, with a birth weight $\geq 4000 \mathrm{~g}$ or in the 90th percentile in terms of gestational age [1]. In recent years, the incidence of fetal macrosomia has increased globally [2-4]. Fetal

\footnotetext{
* Correspondence: llian_w@163.com; zhaoyong@camu.edu.cn

${ }^{5}$ Central Clinical School, Faculty of Medicine, Nursing and Health Sciences, Monash University, 3800 Melbourne, Australia

'School of Public Health and Management, Chongqing Medical University, Chongqing 400016, China

Full list of author information is available at the end of the article
}

macrosomia is suggested to be associated with increased risk of adverse outcomes in the mother and the infant [5]. Some previous studies showed that the most important neonatal complications of macrosomia are shoulder dystocia, perinatal asphyxia, birth injury, hypoglycemia, meconium aspiration syndrome, and death [5-7]. Additionally, fetal macrosomia is likely to lead to obesity, hypertension, and type- 2 diabetes mellitus in adulthood [8]. Fetal macrosomia increases the risk of postpartum hemorrhage, infection, cesarean delivery, prolonged labor, high-degree perineal tears, anesthetic accidents,

(c) The Author(s). 2021 Open Access This article is licensed under a Creative Commons Attribution 4.0 International License, which permits use, sharing, adaptation, distribution and reproduction in any medium or format, as long as you give appropriate credit to the original author(s) and the source, provide a link to the Creative Commons licence, and indicate if changes were made. The images or other third party material in this article are included in the article's Creative Commons licence, unless indicated otherwise in a credit line to the material. If material is not included in the article's Creative Commons licence and your intended use is not permitted by statutory regulation or exceeds the permitted use, you will need to obtain permission directly from the copyright holder. To view a copy of this licence, visit http://creativecommons.org/licenses/by/4.0/. The Creative Commons Public Domain Dedication waiver (http://creativecommons.org/publicdomain/zero/1.0/) applies to the data made available in this article, unless otherwise stated in a credit line to the data. 
and thromboembolism [9]. In 2013, the Chinese government introduced a policy that allows couples, at least one of which is an only child, to have two children; in October 2015, China implemented the universal twochild policy [10]. With a large number of families eager to have two births, the birth peak of two children has come under the influence of national policies, leading to an increase in parity and the consequent increase in pregnancy risks. With the improvement of the living standards of Chinese people, the incidence of fetal macrosomia increased from $6 \%$ in 1995 to $7.8 \%$ in 2005 $[11,12]$. Multiple surveys conducted in various regions of China showed an increase in the incidence of fetal macrosomia. For example, a survey conducted in Harbin, China, showed that the incidence of fetal macrosomia increased from $8.31 \%$ in 2001 to $10.50 \%$ in 2005 [13]. Similarly survey data from Shanghai revealed a $50 \%$ increase in the incidence of fetal macrosomia from 1989 to 1999 [14]. Survey data collected across 14 provinces in China showed a mean macrosomia incidence of $7.3 \%$, ranging from 4.1 to $13.4 \%$ [15].

The causes of fetal macrosomia are complex and mostly remain unexplained. Some risk factors have been identified, and these factors include high pre-pregnancy body mass index (BMI), excessive weight gain during pregnancy, prolonged gestation, male fetal sex, multiparity, maternal age, maternal height, pre-gestational diabetes, and gestational diabetes [16-18]. Among them, parity is one of the important factors affecting the occurrence of fetal macrosomia. Studies showed that the maternal peritoneal and uterine wall of multiparas is more relaxed than that of primiparas. Changes in the uterine cavity volume and the extension of the duration of pregnancy preservation after multiple pregnancies are likely to cause the fetus to be overweight and suffer from fetal macrosomia [16, 19]. As the number of pregnancies increases, the weight of the fetus also increases, along with the risk of macrosomia $[1,16,20-22]$. The study by Akin Usta et al. showed a $64 \%$ multiparity rate among mothers with fetal macrosomia, as well as a significantly higher parity in the macrosomia group than in the control group [23]. However, related studies on the incidence of fetal macrosomia focused on high parity (more than four pregnancies). The impact of one and two fetuses on the incidence of fetal macrosomia has not been fully confirmed in China, especially after the implementation of the universal two-child policy. Therefore, the current research on fetal macrosomia is necessary. We aim to investigate parturients in the Western China cities of Lanzhou and Chongqing via a cross-sectional study to explore the differences in the incidence of fetal macrosomia in first and second pregnancies. We also put forward potential suggestions and policy recommendations to provide a basis for reducing the incidence of fetal macrosomia.

\section{Methods}

\section{Study population and methods}

This study is part of the social science planning project of Chongqing, China, and includes data from the maternal investigation. This cross-sectional study was conducted from August 2017 to January 2018 in three hospitals (two from Chongqing and one from Lanzhou, Gansu). The subject mothers were surveyed 2-3 days after childbirth in the obstetrics and gynecology departments of each hospital. This study used convenience sampling to naturally divide the subjects into the first and second parturient groups. Finally, 1598 pregnant women were included in the study, including 1094 primiparas and 504 women giving birth to their second child. We also examined the participants of the second pregnancy group and further divided it into the fetal and non-fetal macrosomia groups to identify any potential relationships between macrosomia cases in the second child and those in the first child. The inclusion criteria for parturients were a gestational age of more than 37 gestational weeks and successful single births as first and second births. The exclusion criteria are maternal births with third parity and above; complications in pregnancy and childbirth history, such as therioma, pregnancy associated with cardiac disease, and gynecological diseases; and maternal delivery with congenital malformations. The criteria were implemented to exclude potential confounding and bias effects, such as prematurity and diseases in infants.

\section{Questionnaire}

\section{Questionnaire design}

The questionnaire was designed by the Public Nutrition and Health Research group, School of Public Health, Medical University of Chongqing. It was optimized according to the relevant literature and revised according to the pre-survey results. The final version of the survey was constructed after multiple discussions by epidemiologists, statisticians, a nutrition professor, and a health management professor from the Medical University of Chongqing. The questionnaire was self-filled and included the pre-investigation and formal investigation.

\section{Questionnaire content}

The questionnaire consisted of three parts, namely, demographic characteristics, status of health behavior, and pregnancy outcomes. The items on demographic characteristics included ethnicity (Han/minority), only child (Yes/No), height and weight, area (Gansu/Chongqing), residence (town/rural), educational level (primary/ intermediate/senior), marital status (married/unmarried/ divorced or widowed), per capita income of the family $(<4500 ¥ / 4500 ¥$ to $9000 ¥ />9000 ¥)$, and family history (yes, which/no/unknown). The status of health behavior 
included the daily physical activity time $(<30 \mathrm{~min} />30$ min). The pregnancy outcomes included parity (pregnant women in their first pregnancy/pregnant women in their second pregnancy), gender of the newborn (male/ female), maternal $\mathrm{BMI}\left(\mathrm{kg} / \mathrm{m}^{2}\right)$, neonatal weight, fetal macrosomia (yes/no), mode of delivery (normal childbirth/uterine-incision delivery), and pregnancy-related complications (placenta previa/uterine scarring/pregnancy-induced hypertension/cholestasis of pregnancy/ premature rupture of membranes/hydramnion/hypamnion/fetal growth restriction/anemia/thrombocytopenia/ pregnancy associated with cardiac disease/pregnancy combined with thyroid disease/pregnancy with viral hepatitis/AIDS/others/nothing) [24].

\section{Statistical analyses}

Frequencies and percentages values were recorded to describe the demographic characteristics of the first and second pregnancy groups and the second pregnancy group. The mean, standard deviation, Pearson's chisquare test, and $t$ test described the differences in parity and the influential factors of macrosomia in the first and second parturient groups and in the second pregnancy group. Logistic regression analysis was used to explore the differences in the incidence of fetal macrosomia in first and second pregnancies after the adjustment of related variables. These variables are factors that have been identified in previous studies to influence macrosomia incidence, including maternal age (years, <30/ $\geq 30$ ), maternal height $(\mathrm{m})$, delivery weight $(\mathrm{kg})$, maternal BMI $\left(\mathrm{kg} / \mathrm{m}^{2},<30 / \geq 30\right)$, gestational diabetes mellitus (Yes/ No), gestational hypertension (Yes/No), physical activity time (daily) (<30 $\mathrm{min} / \geq 30 \mathrm{~min}$ ), and fetal gender (Male/ Female) [16-18]. The multivariate model was statistically significant (coefficient test $p<0.05$ ) and reached a good fit in the Hosmer and Lemeshow test $(p=0.755)$. Statistical significance was considered at $p<0.05$. All survey data were encoded using Epidata 3.0. Data analyses were carried out using the statistical software Statistical Package for Social Science version 22 (IBM; Armonk, NY, USA).

\section{Results}

\section{Distribution of characteristics among participants}

A total of 1598 pregnant women were included. Table 1 shows the demographic characteristics of the first and second pregnancy groups. These groups included 1094 (68.5\%) primiparas and 504 (31.5\%) women giving birth to their second child. The number of participants who are a single child is lower in the second pregnancy group (20.4\%) than in the first pregnancy group $(32.4 \%)$. The first pregnancy group (80.1\%) reported higher education levels than the second pregnancy group (73.2\%) did.
Table 1 Distribution of characteristics among participants

\begin{tabular}{|c|c|c|c|c|}
\hline Variables & $\begin{array}{l}\text { Pregnant } \\
\text { women in their } \\
\text { first pregnancy } \\
(n, \%)\end{array}$ & $\begin{array}{l}\text { Pregnant women } \\
\text { in their second } \\
\text { pregnancy }(n, \%)\end{array}$ & $x^{2} / t$ & $p$ value \\
\hline \multicolumn{5}{|l|}{ Nationality } \\
\hline Han & $1020(93.2)$ & $464(92.1)$ & & \\
\hline Minority & $74(6.8)$ & $40(7.9)$ & 0.716 & 0.398 \\
\hline $\begin{array}{l}\text { Maternal age } \\
\text { (years) }\end{array}$ & & & 2.207 & $0.027^{*}$ \\
\hline \multicolumn{5}{|l|}{ Single-child } \\
\hline Yes & $354(32.4)$ & $103(20.4)$ & & \\
\hline No & $740(67.6)$ & $401(79.6)$ & 24.016 & $0.000^{* * *}$ \\
\hline \multicolumn{5}{|l|}{ Marital status } \\
\hline Unmarried & $9(0.8)$ & $3(0.6)$ & & \\
\hline Married & $1078(98.5)$ & $498(98.8)$ & & \\
\hline $\begin{array}{l}\text { Divorced or } \\
\text { widowhood }\end{array}$ & $7(0.7)$ & $3(0.6)$ & & \\
\hline \multicolumn{5}{|l|}{ Education level } \\
\hline Basic & $116(10.6)$ & $81(16.1)$ & & \\
\hline Secondary & $102(9.3)$ & $54(10.7)$ & & \\
\hline Higher & $876(80.1)$ & $369(73.2)$ & 11.136 & $0.004^{* *}$ \\
\hline \multicolumn{5}{|l|}{ Location } \\
\hline Lanzhou & $863(78.9)$ & $389(77.2)$ & & \\
\hline Chongqing & $231(21.1)$ & $115(22.8)$ & 0.589 & 0.443 \\
\hline \multicolumn{5}{|l|}{ Residence } \\
\hline Urban & $951(86.9)$ & $444(88.1)$ & & \\
\hline Rural & $143(13.1)$ & $60(11.9)$ & 0.623 & 0.515 \\
\hline \multicolumn{5}{|c|}{ The per capita income of the family } \\
\hline$<4500 ¥$ & $450(41.1)$ & $208(41.2)$ & & \\
\hline $\begin{array}{l}4500 ¥ \text { to } \\
9000 ¥\end{array}$ & $506(46.3)$ & $214(42.5)$ & & \\
\hline$>9000 ¥$ & 133 (12.6) & $82(16.3)$ & 5.424 & 0.066 \\
\hline
\end{tabular}

\section{Univariate analysis of the first and second pregnancy groups}

Table 2 shows the differences in the incidence of macrosomia and macrosomia-related indicators between the first and second pregnancy groups. These variables are factors that have been identified to influence macrosomia incidence in previous studies. We observed no statistical significance in the incidence of fetal macrosomia in the first (7.2\%) and second (7.1\%) pregnancy groups. The delivery weight, maternal BMI, and fetal birth weight of the second pregnancy group $(62.12 \mathrm{~kg}, 23.98$ $\mathrm{kg} / \mathrm{m}^{2}, 3448.73 \mathrm{~g}$ ) were higher than those of the first pregnancy group $\left(60.68 \mathrm{~kg}, 23.31 \mathrm{~kg} / \mathrm{m}^{2}, 3334.63 \mathrm{~g}\right)$. Moreover, the maternal age of the second pregnancy 
Table 2 Univariate analysis of influential factors of macrosomia in the first and second parturient groups

\begin{tabular}{llll}
\hline Variables & $\begin{array}{l}\text { Pregnant women } \\
\text { in their first } \\
\text { pregnancy }(n, \%, \\
\text { mean } \pm \text { SD) }\end{array}$ & $\begin{array}{l}\text { Pregnant women in } \\
\text { their second } \\
\text { pregnancy }(n, \%, \\
\text { mean } \pm \text { SD) }\end{array}$ & $p$ value \\
\hline
\end{tabular}

Fetal macrosomia

$\begin{array}{cllll}\text { Yes } & 79(7.2) & 36(7.1) & & \\ \text { No } & 1015(92.8) & 468(92.9) & 0.003 & 0.955 \\ \text { Maternal } & 29.21 \pm 3.51 & 28.80 \pm 3.39 & 2.207 & 0.027^{*}\end{array}$

age

(years)

$\begin{array}{lllll}\begin{array}{l}\text { Maternal } \\ \text { height } \\ (\mathrm{m})\end{array} & 1.61 \pm 0.05 & 1.61 \pm 0.05 & 1.362 & 0.174 \\ \begin{array}{l}\text { Delivery } \\ \text { weight }\end{array} & 60.68 \pm 8.72 & 62.12 \pm 8.38 & - & 0.002^{* *} \\ (\mathrm{~kg}) & & & 3.109 & \\ \begin{array}{l}\text { Maternal } \\ \text { BMl }(\mathrm{kg} /\end{array} & 23.31 \pm 3.21 & 23.98 \pm 3.08 & - & 0.000^{* * *} \\ \left.\mathrm{~m}^{2}\right) & & & 3.871 & \end{array}$

$\mathrm{m}^{2}$ )

Gestational diabetes mellitus

$$
\begin{array}{ll}
\text { Yes } & 39(3.6) \\
\text { No } & 1055(96.4)
\end{array}
$$

$$
18 \text { (3.6) }
$$$$
486(96.4)
$$$$
0.000 \quad 0.995
$$

Gestational hypertension

$$
\begin{array}{ll}
\text { Yes } & 39(3.6) \\
\text { No } & 1055(96.4)
\end{array}
$$

$$
471(93.5)
$$

\begin{tabular}{|c|c|c|c|c|}
\hline Male & $587(53.7)$ & $268(53.2)$ & & \\
\hline Female & $507(46.3)$ & $236(46.8)$ & 0.032 & 0.858 \\
\hline
\end{tabular}$$
7.1340 .008
$$

Physical activity time (daily)

$\begin{array}{llr}<30 & 873(79.8) & 409(81.2) \\ \text { min } & & \\ \geq 30 & 221(20.2) & 95(18.8) \\ \text { min } & & \\ \begin{array}{l}\text { Fetal } \\ \text { birth }\end{array} & 3334.63 \pm 620.82 & 3448.73 \pm 758 \\ \text { weight } & & \\ \end{array}$

(g)

Fetal gender

group (28.80 years) was lower than that of the first pregnancy group (29.21 years).

\section{Univariate analysis of second-time pregnant mothers}

Table 3 shows the difference in first pregnant macrosomia incidence and macrosomia influence factors of the second-time pregnant mothers. The case of mothers who have given birth to a second child with macrosomia (5.5\%) was not related to whether the first child had

\begin{tabular}{|c|c|c|c|c|}
\hline Variables & $\begin{array}{l}\text { The second child is } \\
\text { fetal macrosomia } \\
(n, \% \text {, mean } \pm \text { SD) }\end{array}$ & $\begin{array}{l}\text { The second child is } \\
\text { non-fetal macroso- } \\
\text { mia ( } n, \% \text {, mean } \pm \\
\text { SD) }\end{array}$ & $x^{2} / t$ & $\begin{array}{l}p \\
\text { value }\end{array}$ \\
\hline \multicolumn{5}{|c|}{ The first child is fetal macrosomia } \\
\hline Yes & $2(5.5)$ & $22(4.7)$ & & \\
\hline No & $34(94.5)$ & $446(95.3)$ & 0.000 & 0.999 \\
\hline $\begin{array}{l}\text { Maternal } \\
\text { age } \\
\text { (years) }\end{array}$ & $27.75 \pm 2.39$ & $28.88 \pm 3.45$ & - & $0.012^{*}$ \\
\hline $\begin{array}{l}\text { Maternal } \\
\text { height } \\
\text { (m) }\end{array}$ & $161.61 \pm 5.00$ & $160.92 \pm 4.85$ & 0.819 & 0.413 \\
\hline $\begin{array}{l}\text { Delivery } \\
\text { weight } \\
\text { (kg) }\end{array}$ & $63.92 \pm 8.01$ & $61.99 \pm 8.41$ & 1.332 & 0.184 \\
\hline $\begin{array}{l}\text { Maternal } \\
\text { BMl (kg/ } \\
\left.\mathrm{m}^{2}\right)\end{array}$ & $24.47 \pm 2.95$ & $23.94 \pm 3.09$ & 1.006 & 0.315 \\
\hline \multicolumn{5}{|c|}{ Gestational diabetes mellitus } \\
\hline Yes & $2(5.5)$ & $16(3.4)$ & & \\
\hline No & $34(94.5)$ & $452(96.6)$ & 0.040 & 0.842 \\
\hline \multicolumn{5}{|c|}{ Gestational hypertension } \\
\hline Yes & $2(5.5)$ & $20(4.3)$ & & \\
\hline No & $34(94.5)$ & $448(95.7)$ & 0.000 & 0.999 \\
\hline \multicolumn{5}{|c|}{ Physical activity time (daily) } \\
\hline $\begin{array}{l}<30 \\
\min \end{array}$ & $34(94.5)$ & $376(80.3)$ & & \\
\hline $\begin{array}{l}\geq 30 \\
\min \end{array}$ & $2(5.5)$ & $92(19.7)$ & 4.382 & $0.036^{*}$ \\
\hline \multicolumn{5}{|c|}{ Fetal gender } \\
\hline Male & $20(55.6)$ & $249(53.2)$ & & \\
\hline Female & $16(44.4)$ & 219 (46.8) & 0.074 & 0.785 \\
\hline
\end{tabular}
macrosomia (4.7\%). The mothers in the non-fetal macrosomia group (28.88 years) were older than those in the fetal macrosomia group (27.75 years), and they
Table 3 Univariate analysis of factors that influence macrosomia in second-time pregnant mothers

${ }^{*} p<0.05 . S D$ standard deviation, $B M I$ body mass index

Maternal BMI refers to the last weight recorded before delivery

(19.7\%) were trend to be more engage in physical activity than those in the fetal macrosomia group (5.5\%).

\section{Multivariate logistic regression analysis}

Table 4 shows the multivariate logistic regression model of the differences in the incidence of fetal macrosomia in the first and second pregnancies after adjusting for potentially related confounding variables. As shown in Table 4, parity (first and second pregnancies) has no effect on the occurrence of macrosomia after adjusting the related variables. Mothers older than 30 years are not likely to give birth to infants with macrosomia (OR 0.6, 95\% CI 0.4, 0.9) 
Table 4 Bivariate logistic regression analysis of factors that affect delivery involving fetal macrosomia

\begin{tabular}{|c|c|c|c|c|c|}
\hline Variables & & $B$ & $x^{2}$ & $p$ value & OR $(95 \% \mathrm{Cl})$ \\
\hline \multicolumn{6}{|l|}{ Parity } \\
\hline Pregnant women in their first pregnancy & $1094(68.5)$ & & & & 1 \\
\hline Pregnant women in their second pregnancy & $504(31.5)$ & -0.048 & 0.053 & 0.818 & $0.9(0.6,1.4)$ \\
\hline \multicolumn{6}{|l|}{ Maternal age } \\
\hline$<30$ & 939 (58.8) & & & & 1 \\
\hline$\geq 30$ & $659(41.2)$ & -0.515 & 5.963 & $0.015^{*}$ & $0.6(0.4,0.9)$ \\
\hline \multicolumn{6}{|l|}{ Maternal height } \\
\hline$<1.60$ & $495(31.0)$ & & & & \\
\hline$\geq 1.60$ & $1103(69.0)$ & & & & \\
\hline \multicolumn{6}{|l|}{ Maternal BMI } \\
\hline$<30$ & $1547(96.8)$ & & & & 1 \\
\hline$\geq 30$ & $51(3.2)$ & 0.747 & 3.029 & 0.082 & $2.1(0.9,4.9)$ \\
\hline \multicolumn{6}{|l|}{ Gestational diabetes mellitus } \\
\hline Yes & $57(3.6)$ & 0.180 & 0.138 & 0.710 & $1.2(0.5,3.1)$ \\
\hline No & $1541(96.4)$ & & & & 1 \\
\hline \multicolumn{6}{|l|}{ Gestational hypertension } \\
\hline Yes & $72(4.5)$ & 0.582 & 2.376 & 0.123 & $1.8(0.9,3.8)$ \\
\hline No & $1526(95.5)$ & & & & 1 \\
\hline \multicolumn{6}{|l|}{ Physical activity time (daily) } \\
\hline$<30 \min$ & $1282(80.2)$ & 0.449 & 2.585 & 0.108 & $1.6(0.9,2.7)$ \\
\hline$\geq 30 \min$ & $316(19.8)$ & & & & 1 \\
\hline \multicolumn{6}{|l|}{ Fetal gender } \\
\hline Male & $855(53.5)$ & & & & 1 \\
\hline Female & $743(46.5)$ & -0.028 & 0.020 & 0.888 & $1.0(0.7,1.4)$ \\
\hline
\end{tabular}

${ }^{*} p<0.05$. BMI body mass index, $\mathrm{OR}$ odds ratio, $\mathrm{Cl}$ confidence interval Maternal BMI refers to the last weight recorded before delivery

\section{Discussion}

With the improvement of the living standards of Chinese people, the incidence of fetal macrosomia has increased [11-15]. The increase in maternal parity after the implementation of the universal two-child policy has resulted in the relaxation of the peritoneum and uterine wall, an increase in uterine volume, and an extension of the duration of pregnancy preservation after multiple pregnancies; these conditions lead to an increased risk of macrosomia [1, 16, 19-22]. We assume that macrosomia incidence in second children will increase. However, our study showed that no statistical significance was found in the incidence of fetal macrosomia in the first and second pregnancy groups. Additionally, the birth of a second child with macrosomia was not significantly related to the occurrence of macrosomia in the first child. However, this finding is not without practical significance. Some studies have shown that increased parity is associated with a high risk of fetal macrosomia [21, 22]. In a study from Sack, mothers with multiple pregnancies had a higher risk of having fetal macrosomia than those in the control group did [22]. Dor et al. reported that the multiparity rate was approximately $70 \%$ in the case group [21]. Similarly, the study of Akin Usta et al. showed a multiparity rate of $64 \%$ among mothers with fetal macrosomia and a significantly higher parity in the macrosomia group than in the control group [23]. Results from the aforementioned studies are based on mothers with more than two pregnancies. By contrast, the current study focused on only the first and second pregnancies. Therefore, potentially removing the effects of peritoneal and uterine walls and the uterine cavity volume of pregnant women on giving birth to a second child is possible. In the context of China's "two-child policy," we have strong evidence that suggests that Chinese mothers may not have to be concerned with the possibility of having a second child with macrosomia. The prevention of fetal macrosomia may primarily start with lifestyle intervention.

This study found that mothers older than 30 years are not likely to give birth to babies with macrosomia. This result varies from foreign research. Some foreign studies 
discovered that mothers aged 30 years may be at risk for macrosomia [16]. A population in the UK showed that the incidence of macrosomia in women between 35 and 39 years increased by $40 \%$ relative to women under 35 years old [25]. Our research also showed that the compared with those in the second pregnancy group, the mothers in the first pregnancy group were older and received higher education. We speculate that this result may be due to the fact that relative to pregnant women under the age of 30, pregnant women over the age of 30 in China are more educated and have better cognition of maternal and child health care. Studies also showed that mothers with higher education have a lower risk of macrosomia than mothers without higher education have [26]. However, mothers in their second pregnancy may possibly have extensive knowledge or education about pregnancy-related health. Education has been recognized as the most important social factor affecting the health of mothers and children [27]. Health and perinatal-educated mothers can maintain a healthy lifestyle, which is important for avoiding poor perinatal outcomes [26]. Previous studies showed that the risk factors for perinatal outcomes such as macrosomia are clearly related to perinatal education $[28,29]$. Although the first pregnancy group reported higher education levels, the second pregnancy group had more perinatal experience, which may be the reason why no significant difference was found in the macrosomia incidence between the first and second pregnancy groups. In the context of China's universal two-child policy, we believe that community and health departments should strengthen perinatal health education, which potentially plays an important role in preventing macrosomia and other adverse pregnancy outcomes. In addition, gestational diabetes and gestational hypertension during pregnancy are very important risk factors affecting the output of huge babies [16-18]. However, because this is a cross-sectional study, it is impossible to know exactly when the pregnant woman suffered from gestational diabetes and/or hypertension in pregnancy, and it is uncertain whether she has been treated at the survey site during her illness, so that it cannot be proved. The causal relationship between the output of giant children has certain limitations. This suggests that in the future we can establish a cohort study to further explore the relationship between the disease and the output of macrosomia in combination with clinical biochemical indicators and public health nutritional indicators, so as to observe that pregnant women are affected by gestational diabetes and/or gestational hypertension, and the connection between control and huge output.

We found that the occurrence of macrosomia in the second child was not significantly affected by whether the first child was born with macrosomia. This finding may indicate that for two pregnancies of the same woman, the birth of a second child with macrosomia is not related to whether the first child had macrosomia. The duration of daily physical activity of the non-fetal macrosomia group was greater than that of the macrosomia group. This result is consistent with those of previous studies. The American College of Obstetricians and Gynecologists, the Royal College of Obstetricians and Gynaecologists, and the Royal College of Midwives collectively recommend $30 \mathrm{~min}$ of daily moderate-intensity physical activity for low-risk pregnant women regardless of the stage of pregnancy [30-32]. Regular physical activity can lower the risk of gestational diabetes and thus reduce the macrosomia incidence [31, 33, 34]. However, many Caucasian women with higher education and income and those who plan to not have other children in the family think that activities may be unsafe, exhausting, and uncomfortable, hence their inactivity [35, 36]. In sum, reasonable and regular physical exercise during pregnancy can effectively reduce the occurrence of macrosomia.

\section{Limitations of the study}

The limitations of the study include the following. First, we chose only two regions of Western China to conduct surveys, and thus, our work cannot fully reflect the reality of China as a whole. Second, our data were collected within 5 months, and seasonal variations could lead to time bias. Third, in response to the hospital's request, we conducted a questionnaire survey using a registered form. The respondents could have been worried about revealing personal information and thus concealed facts, which could cause information bias. Finally, taking into account the small sample size of this survey and the limited population of the survey, it may be possible to expand the sample size in future studies to verify the clear relationship between effect indicators and outcome indicators. All these potential limitations should be considered when the results are interpreted.

\section{Conclusions}

The incidence of macrosomia in Western China might not be affected by second childbirth and is not increased by low parity.

\footnotetext{
Abbreviations

BMI: Body mass index; SD: Standard deviation; OR: Odds ratio; Cl: Confidence interval; AIDS: Acquired immune deficiency syndrome

\section{Acknowledgements}

We are grateful to the following who contributed to this research: the investigators in the two hospitals in Chongqing and in the Lanzhou Maternal and Child Health Care Hospital; the undergraduate students of the Medical University of Chongqing who participated in the questionnaire survey; Doctor Lianlian Wang and Professor Yong Zhao for serving as the chief executive of the project; and Xianglong Xu, Xueqing Liu, Huan Zeng, Mao
} 
Zeng, and Fan Zhang of the School of Public Health of Chongqing Medical University for their contributions to this article.

\section{Authors' contributions}

Yong Zhao and Li Luo conceived and designed the study. Lianlian Wang wrote the protocols. Lianlian Wang, Xueging Liu, and Li Luo recruited the participants and collected the survey data. Li Luo wrote the manuscript draft, analyzed the data, and interpreted the results. Xueqing Liu and Xianglong Xu reviewed and edited manuscript. Mao Zeng analyzed the data, reviewed, and edited the writing. Yong Zhao helped in the manuscript preparation. All authors have given final approval of this version of the manuscript.

\section{Funding}

The research was funded by the authors.

\section{Availability of data and materials}

The datasets used and analyzed during the current study are available from the corresponding author on reasonable request.

\section{Declarations}

\section{Ethics approval and consent to participate}

This research was performed in accordance with the Declaration of Helsinki and approved by the Ethical Committee of Chongqing Medical University (ethical approval code: 2016001). All participants were informed of the purpose of the study and their cooperation was voluntary, and they submitted signed informed consent.

\section{Consent for publication}

Not applicable

\section{Competing interests}

The authors declare no conflict of interests.

\section{Author details}

${ }^{1}$ School of Public Health and Management, Chongqing Medical University, Chongqing 400016, China. ${ }^{2}$ Research Center for Medicine and Social Development, Chongqing Medical University, Chongqing 400016, China. ${ }^{3}$ Collaborative Innovation Center of Social Risks Governance in Health, Chongqing Medical University, Chongqing 400016, China. ${ }^{4}$ Chengdu Center for Disease Control and Prevention, 610041 Chengdu, China. ${ }^{5}$ Central Clinical School, Faculty of Medicine, Nursing and Health Sciences, Monash University, 3800 Melbourne, Australia. ${ }^{6}$ The Department of Obstetrics, The First Affiliated Hospital of Chongqing Medical University, 400016 Chongqing, China. ${ }^{7}$ Department of Reproduction Health and Infertility, The First Affiliated Hospital of Chongqing Medical University, 400016 Chongqing, China. ${ }^{8}$ Canada-China-New Zealand Joint Laboratory of Maternal and Fetal Medicine, Chongqing Medical University, 400016 Chongqing, China.

\section{Received: 9 November 2018 Accepted: 31 March 2021} Published online: 13 April 2021

\section{References}

1. Koyanagi A, Zhang J, Dagvadorj A, Hirayama F, Shibuya K, Souza JP, et al. Macrosomia in 23 developing countries: an analysis of a multicountry, facility-based, cross-sectional survey. Lancet. 2013;381(9865):476-83. https:// doi.org/10.1016/S0140-6736(12)61605-5.

2. Yeh J, Shelton J. Reasons for increasing trends in large for gestational age births. Obstetrics Gynecol. 2004;104(4):720-6.

3. Martin JA, Hamilton BE, Sutton PD, et al. Births: Final Data for 2006. Natl Vital Stat Rep. 2009;57(7):1-120.

4. Onyiriuka AN. High birth weight babies: incidence and foetal outcome in a mission hospital in Benin City, Nigeria. Nigerian J Clin Pract. 2006;9(2):114-9.

5. Campbell S. Fetal macrosomia: a problem in need of a policy. Ultrasound Obstetrics Gynecol. 2014;43(1):3-10. https://doi.org/10.1002/uog.13268.

6. Heiskanen N, Raatikainen K, Heinonen S. Fetal macrosomia--a continuing obstetric challenge. Biol Neonate. 2006;90(2):98-103. https://doi.org/10.1159/ 000092042.

7. Esakoff TF, Cheng YW, Sparks TN, et al. The association between birthweight $4000 \mathrm{~g}$ or greater and perinatal outcomes in patients with and without gestational diabetes mellitus. Am J Obstetrics Gynecol. 2009;200(6):672 e1672.e4.

8. Boney CM, Verma A, Tucker R, Vohr BR. Metabolic syndrome in childhood: association with birth weight, maternal obesity, and gestational diabetes mellitus. Pediatrics. 2005;115(3):e290-6. https://doi.org/10.1542/peds.2004-1 808.

9. Boulet SL, Alexander GR, Salihu HM, Pass MA. Macrosomic births in the united states: determinants, outcomes, and proposed grades of risk. Am J Obstetrics Gynecol. 2003;188(5):1372-8. https://doi.org/10.1067/mob.2003.302.

10. Zeng $Y$, Hesketh T. The effects of China's universal two-child policy. Lancet. 2016;388(10054):1930-8. https://doi.org/10.1016/S0140-6736(16)31405-2.

11. Shouyong, Xiaofei, Liang, et al. Risk factors and long-term health consequences of macrosomia: a prospective study in Jiangsu Province, China. J Biomed Res. 2012;26(4):235.

12. Lu Y, Zhang J, Lu X, Xi W, Li Z Secular trends of macrosomia in southeast China, 1994-2005. Bmc Public Health. 2011; 11(1):1-9, DOl: https://doi.org/1 0.1186/1471-2458-11-818.

13. Bao C, Zhou Y, Jiang L, Sun C, Wang F, Xia W, et al. Reasons for the increasing incidence of macrosomia in Harbin, China. BJOG. 2011;118(1):938. https://doi.org/10.1111/j.1471-0528.2010.02776.x.

14. Zhu L, Qin X, Qian S. Macrosomia and associated risk factors in Shanghai. Chin J Birth Heredity (In Chinese). 2001;9:81-3.

15. Li G, Kong L, Li Z, et al. Prevalence of macrosomia and its risk factors in China: a national survey in 201 I. Chin J Perinatal Med. 2013;16(9):546-50.

16. Said AS, Manji KP. Risk factors and outcomes of fetal macrosomia in a tertiary centre in Tanzania: a case-control study. Bmc Pregnancy Childbirth. 2016;16(1):243. https://doi.org/10.1186/s12884-016-1044-3.

17. Chatfield J. ACOG issue guidelines on fetal macrosomia. Am Fam Physician. 2001;64(1):169-70.

18. Li Y, Liu QF, Zhang D, et al. Weight gain in pregnancy, maternal age and gestational age in relation to fetal macrosomia. Natl Nutr Sci Conference. 2015:4(2):104-9.

19. Chen W, Wu M, Zhang D, et al. Occurrence and influencing factors of macrosomia. Chin J Obstetrics Gynecol Pediatrics (Electronic Edition). 2013;9(4):397-401.

20. Rao J, Fan D, Wu S, et al. Trend and risk factors of low birth weight and macrosomia in south China, 2005-2017: a retrospective observational study. Sci Rep. 2018;8(1):3393.

21. Dor N, Mosberg H, Stern W, Jagani N, Schulman H. Complications in fetal macrosomia. N Y State J Med. 1984;84(6):302-5.

22. Sack RA. The large infant. A study of maternal, obstetric, fetal, and newborn characteristics; including a long-term pediatric follow-up. Am J Obstetrics Gynecol. 1969;104(2):195

23. Usta A, Sancakliusta C, Savkli A. Frequency of fetal macrosomia and the associated risk factors in pregnancies without gestational diabetes mellitus. Pan Afr Med J. 2017;26:e189.

24. Wang L, Xu X, Baker P, Tong C, Zhang L, Qi H, et al. Patterns and associated factors of caesarean delivery intention among expectant mothers in China: implications from the implementation of China's new national two-child policy. Int J Environ Res Public Health. 2016;13(7):686. https://doi.org/10.33 90/ijerph13070686.

25. Jolly MC, Sebire NJ, Harris JP, Regan L, Robinson S. Risk factors for macrosomia and its clinical consequences: a study of 350,311 pregnancies. Eur J Obstetrics Gynecol Reprod Biol. 2003;111(1):9-14. https://doi.org/10.1 016/S0301-2115(03)00154-4.

26. Juárez S, Revuelta-Eugercios BA, Ramiro-Fariñas D, Viciana-Fernández F. Maternal education and perinatal outcomes among Spanish women residing in Southern Spain (2001-2011). Matern Child Health J. 2014;18(8): 1814-22. https://doi.org/10.1007/s10995-013-1425-4.

27. Kramer MS, Séguin L, Lydon J, et al. Socio-economic disparities in pregnancy outcome: why do the poor fare so poorly? Paediatric Perinatal Epidemiol. 2000; 14(3):194-210. https://doi.org/10.1046/j.1365-3016.2000.00266.x.

28. Voldner N, Froslie $K$, Bo K, et al. Modifiable determinants of fetal macrosomia: role of lifestyle-related factors. Acta Obstetricia et Gynecologica Scandinavica. 2008;87(4):423-9. https://doi.org/10.1080/0001 6340801989825

29. Bergmann RL, Richter $\mathrm{R}$, Bergmann $K E$, et al. Secular trends in neonatal macrosomia in Berlin: influences of potential determinants. Paediatric Perinatal Epidemiol. 2010;17(3):244-9.

30. Royal College of Obstetricians and Gynaecologists: Exercise in pregnancy (RCOG Statement 4). Accessed October 29, 2015 [Published 2006]. https:// www.rcog.org.uk/womens-health/clinical-guidance/exercise-pregnancy. 
31. American College of Obstetricians and Gynecologists committee opinion. Exercise during pregnancy and the postpartum period. Number 267, January 2002. American College of Obstetricians and Gynecologists. Int J Gynaecol Obstet. 2002:77(1):79-81.

32. Munro J. RCM comment on physical activity in pregnancy guidelines 04-0213_2. Accessed June 4, 2015. https://www.rcm.org.uk/college/about/mediacentre/press-releases/rcm-comment-on-physical-activity-in-pregnancyguidelines.

33. Wang $C$, Wei $Y$, Zhang $X$, Zhang $Y$, Xu Q, Sun $Y$, et al. A randomized clinical trial of exercise during pregnancy to prevent gestational diabetes mellitus and improve pregnancy outcome in overweight and obese pregnant women. Am J Obstetrics Gynecol. 2017;216(4):340-51. https://doi.org/10.101 6/j.ajog.2017.01.037.

34. Nascimento SL, Surita FG, Cecatti JG. Physical exercise during pregnancy: a systematic review. Curr Opin Obstetrics Gynecol. 2012;24(6):387-94. https:// doi.org/10.1097/GCO.0b013e328359f131.

35. Duncombe D, Wertheim EH, Skouteris H, Paxton SJ, Kelly L. Factors related to exercise over the course of pregnancy including women's beliefs about the safety of exercise during pregnancy. Midwifery. 2009;25(4):430-8. https://doi.org/10.1016/j.midw.2007.03.002.

36. Gaston A, Cramp A. Exercise during pregnancy: a review of patterns and determinants. J Sci Med Sport. 2011;14(4):299-305. https://doi.org/10.1016/j. jsams.2011.02.006

\section{Publisher's Note}

Springer Nature remains neutral with regard to jurisdictional claims in published maps and institutional affiliations.

Ready to submit your research? Choose BMC and benefit from:

- fast, convenient online submission

- thorough peer review by experienced researchers in your field

- rapid publication on acceptance

- support for research data, including large and complex data types

- gold Open Access which fosters wider collaboration and increased citations

- maximum visibility for your research: over $100 \mathrm{M}$ website views per year

At $\mathrm{BMC}$, research is always in progress.

Learn more biomedcentral.com/submissions 